\title{
Neuropeptides as regulators of behavior in insects
}

\author{
Liliane Schoofs, Arnold De Loof, Matthias Boris Van Hiel \\ Functional Genomics and Proteomics Group, Department of Biology, KU Leuven, Belgium; email: \\ liliane.schoofs@kuleuven.be, arnold.deloof@kuleuven.be, boris.vanhiel@kuleuven.be
}

\section{Keywords}

neuropeptide, insect, behavior, neuronal circuit, G protein coupled receptor, Drosophila

\begin{abstract}
Neuropeptides are by far the largest and most diverse group of signaling molecules in multicellular organisms. They are ancient molecules important in regulating a multitude of processes. Their small proteinaceous character allowed them to quickly evolve and radiate into a multitude of different molecules. On average some hundred distinct neuropeptides are present in animals, with sometimes unique classes that do not occur in distantly related species. Acting as neurotransmitters, neuromodulators, hormones or growth factors, they are extremely diverse and are involved in controlling growth, development, ecdysis, digestion, diuresis and many more physiological processes. Neuropeptides are also crucial in regulating all kinds of behavioral actions associated with feeding, courtship, sleep, learning and memory, stress, addiction and social interactions. In general, behavior ensures that an organism can survive in its environment and is defined as any action that can change an organism's relationship to its surroundings. Even though the mode of action of neuropeptides in insects is vigorously studied, relatively little is known about most neuropeptides and even then only a few model insects are investigated. Here, we will give an overview of the roles of neuropeptides in insect behavior. We conclude that multiple neuropeptides need to work in consort to coordinate a certain behavior. Additionally, most studied neuropeptides have more than a single function.
\end{abstract}

\section{Introduction}

Ever since the groundbreaking work of Karl von Frisch, who deciphered the meaning behind the waggle and round dance performed by scouting bees (136), it became gradually more clear that insects are not mere automatons, but complex organisms with intricate behaviors. Nowadays it is obvious that insects are highly evolved organisms, with a sophisticated central nervous system (CNS). However, this was not always so. Linnaeus, the father of taxonomy, classified insects as having no brain (86). While their brain size is nowhere near that of humans, this does not mean they are, as is still assumed by most people, mindless critters. Humans possess some 100 billion neurons. Insects, on average, survive with 100,000 times less nerve cells. But as Chittka and Niven argue, bigger brains aren't necessarily better (31). Even with a tiny brain, insects are capable of very complex behavior. Honey bees are able to conduct at least 59 distinct behavioral actions, more than is known for any rodent and about half that of a human child or bottlenose dolphin $(29,31)$. Insects have the capacity to learn rules and generalize them across sensory modalities. Their sensory systems often match or surpass ours. Moreover, insects appear to be capable of grasping concepts such as above/below (9) or sameness/different (48), numerosity discrimination (the ability to distinguish between sets of more or less items) (23) and 
counting $(33,104)$. They can solve complex problems $(10,40,162)$, recognize faces of members of their own species $(38,119)$, display Pavlovian behavior $(113,141)$, show pessimistic or optimistic tendencies (i.e. be “down") (12) and can even be "heartbroken"(120).

There is increasing compelling evidence that these behaviors, be they of complex cognitive character or merely basic locomotive, are in some way regulated by specific signaling molecules known as neuropeptides, small proteins released by neurons and/or neurosecretory cells. Neuropeptides can act as neurotransmitters, hormones, neuromodulators and growth factors. They are processed from their larger, inactive precursors by enzymes, i.e. proprotein convertases or furins that recognize specific cleavage sites. After cleavage, carboxypeptidases E or D remove the mono- or dibasic amino acids and in many cases, PAM (Peptidyl glycine alpha-Amidating Monooxygenase) or its invertebrate ortholog, catalyzes the conversion of the carboxyterminal glycine into an amidated residue (45). The mature, bioactive neuropeptides are formed while their precursors are transported within secretory granules from the Golgi to the cell membrane, where they are released. Bear in mind that classical neurotransmitters are produced at the synaptic terminus and are only released in situ. Neuropeptides act on target cells, usually through interaction with specific membrane receptors, known as G protein-coupled receptors (GPCRs). These GPCRs usually connect to an intracellular protein kinase cascade or second messengers such as $\mathrm{Ca}^{2+}$ or cAMP. Because of these cascades, neuropeptides can exert a variety of effects. This is in stark contrast to aminergic neurotransmitters which usually only alter the excitability of their target cells.

\section{Origin of neuropeptides}

Insects possess a wide range of neuropeptides. Some of them display a high resemblance to vertebrate neuropeptides such as Neuropeptide F, tachykinins or sulfakinins. Other insect neuropeptides such as proctolin or eclosion hormone (EH) are unique to arthropods (102). The common ancestors of metazoans, choanoflagellates and filastereans already possessed a wide variety of gene families controlling multicellularity and development. The ancient origin of neuropeptides dates back to at least 600 million years ago, as they are not only found in Cnidaria, supposed to be the oldest animals with a nervous system, to which belong the polyps, jellyfish, corals and anemones $(106,127)$, but also in Ctenophora (97) and Placozoa (121). According to recent phylogenetic analyses, both might be basal to Cnidaria (57). Placozoans are quite simple, soft-bodied animals, lacking three germ layers, neurons, synapses, muscles and a true gut. But they can coordinate cells to move or contract (62). Neuropeptides might therefore be even older. Cnidarian neuropeptides are able to induce settling behavior in sponge larvae (144). Sponges are considered a sister lineage to true animals and contain a rich repertoire of rhodopsin-type GPCRs. Our analysis of the genome of the sponge Amphimedon queenslandica and several sponge transcriptomes reveals several hypothetical neuropeptides, separated within their precursors by typical dibasic cleavage sites as well as amidation sites. None of these mined neuropeptides displays any recognizable homologies to known neuropeptides, but cross-lineage conservation of neuropeptides is often limited to a few residues. Nevertheless, the sponge genome also harbors the well-conserved processing enzymes, such as PAM (XP_003388865.2), furins (XP_011405480, XP_011404107, XP_003387614), proprotein convertases (XP_011405715, XP_011405715, XP_011404106, XP_011405930, XP_011407660) and carboxypeptidase D (XP_003384134), which are required for cleavage and maturation of neuropeptides from their precursors. Even the genome of the choanoflagellates encodes homologs of neuropeptide signaling and GPCR genes. All these findings suggest that neuropeptide signaling already occurred in the progenitors of metazoans and choanoflagellates (41) and thus predates the emergence of neuronal tissue. Early neural systems might have been neuropeptidergic rather than aminergic, because ctenophores do not use 
serotonin, acetylcholine, dopamine, noradrenaline, adrenaline, octopamine, histamine or glycine as neurotransmitters, suggesting that these amines were recruited later in evolution.

\section{Neuropeptides and insect behavior}

Sensory stimuli detected by GPCRs elicit stereotypical animal behavior that is composed of combinations of different motor patterns, which can vary depending on the external environment or internal states. The recruitment of appropriate motor programs as a result of changing conditions is an essential aspect of animal behavior. How sensory cues or internal states are perceived by the brain and subsequently transformed into appropriate decisions and actions is poorly understood. Neuromodulators such as neuropeptides or monoamines are known to change output motor patterns by reconfiguring the dynamics of neuronal circuits (11). They modulate neural circuits by changing the activity of the composing neurons or the synaptic efficacy of the neural connections, or by other yet unknown mechanisms.

How neuropeptides change the information flow within neuronal circuits remains largely elusive. Insects are ideal model organisms to study the underlying molecular mechanism of hard-wired innate behavioral responses as well as of behaviors acquired by learning and memory. Here, we will review the state of the art on the roles of neuropeptides in various insect behaviors. Although neuropeptides also have roles in physiological processes, including growth and development, digestion, energy homeostasis, water balance, metabolism, amongst others, these fall outside the scope of this review. We will also not include the effects of neuropeptides on ecdysis behavior as there is an excellent recent review on this topic (145).

\section{Neuropeptides in feeding behavior}

Similar to mammals, insects consume food for its reward value. In Drosophila, the circuit mechanism is mediated by conserved dopamine and Neuropeptide F signaling (140). Feeding behavior can be subdivided into discrete parts. First, an animal will experience a lack of energy that is interpreted as hunger. The animal starts to forage for food. Once a food source is detected, the animal will initiate feeding and will eat until a satiety signal urges it to disengage from the food. The amount of food an insect ingests depends on a lot of factors, such as age, nutritional state, environment and activity. It is therefore not surprising that numerous neuropeptides affect this behavior. The amount of ingested food is easy to measure and is therefore often used to monitor the effect of neuropeptides. For instance, sulfakinins (SK), which resemble the vertebrate gastrin/cholecystokinin peptides, inhibit food intake in a multitude of insects, including cockroaches, bugs, locusts and flies, possibly by stimulating contractions of the gut (8). Injection of SKs significantly decrease food uptake in $5^{\text {th }}$ instar locusts (142, 161). In cockroaches, SK induced reduction in food intake reaches as much as $84 \%$ (89). In line with this, RNAi of SK increases consumption in crickets and the red flour beetle Tribolium castaneum (93, 160). In Drosophila, drosulfakinins induce satiety, possibly by affecting transcription of insulin-like peptides. DSK RNAi in insulin-producing cells (IPCs) results in increased food uptake and causes aberrant food choice behavior (123). The effects of SK on feeding might be regulated through short Neuropeptide F (sNPF). The sulfakinin receptor is highly expressed in the corpora cardiaca (CC), an organ that in several insects also contains $\operatorname{sNPF}(21,36,94,107)$. sNPF is a potent orexic peptide, abundantly expressed in the CNS $(81,101)$. In fruit flies, overexpression of sNPF increases food consumption resulting in bigger flies, while loss-of-function mutants display the opposite phenotype $(54,81)$. Interfering with sNPF doesn't, however, affect the behavioral switch from feeding to wandering 
larvae. In the silkworm, injection of sNPF results in accelerated onset of feeding (99), suggesting a role in feeding initiation.

Starvation increases the response towards stimuli as distinct as food odorants, repellents and pheromones. Both sNPF and CCHamide modulate these starvation effects. The expression of sNPF in numerous olfactory receptor neurons (ORNs) in the antenna and maxillary palps of adult $D$. melanogaster suggests a role in adult food-seeking behavior (24). Indeed, upon starvation, elevated SNPF levels as well as increased expression of sNPFR, are seen in the ORNs in the antennal lobes of flies, suggesting that SNPF is at least partly responsible for starvation-dependent food-seeking behavior (111). This effect can be blocked by constitutive activation of the insulin receptor, showing that high insulin levels act as a satiety signal, blocking the elevated SNPFR expression. In the cockroach Periplaneta americana SNPF titers rise dramatically upon 4 weeks starvation. Moreover, sNPF is able to activate the locomotor program in fed animals, while CCAP inhibits this activity in starved cockroaches (95).

Ko and co-workers showed that SNPF enhances attraction to odors in starved flies and that tachykinin suppresses the activity of neurons wired for aversion in hungry flies (73). These studies show that both sNPF and tachykinin have a stimulatory effect on feeding. Nonetheless, in some insects, sNPF has negative effects on feeding. For instance, in the mosquito Aedes aegypti, injection of sNPF-3 reduces host-seeking behavior (84). In S. gregaria, sNPF injection decreases food uptake, while RNAi has the opposite effect $(36,37)$. In the red imported fire ant, starvation causes a decrease in sNPF expression (30). As the evolutionary distance between these insects is large, the switch to an inhibitory role of sNPF on feeding most likely happened multiple times.

Another neuropeptide involved in feeding behavior in insects is Neuropeptide F. NPF is structurally related to vertebrate NPY, well known for its ability to increase food intake (32). In D. melanogaster, NPF overexpression induces continuous feeding in larvae and increases the tolerance to noxious food $(150,151)$. Stimulation of NPF-expressing neurons mimics food deprivation while blocking $n p f r 1$ containing neurons suppresses memory performance in hungry flies, showing its involvement in appetitive memory (74). Besides the brain, NPF is found in midgut cells of larvae and adults and in the suboesophageal ganglion (SOG), further implying a role in feeding $(13,20)$. Wang and co-workers showed that brief presentation of appetitive odors urge fed larvae to impulsively feed. Deficiencies in NPF-signaling blocks this feeding by disrupting dopamine-mediated olfactory processing (140). This is in line with the observation that silencing NPF neurons or NPFR abolishes food-odor attractiveness, while enhanced NPF activity displays an increased attraction to aversive odors and noxious food (16, 151). NPFR1 neuroactivity might be mediated by the insulin/insulin-like growth factor signaling pathway (IIS) as upregulation of this pathway suppresses attraction to noxious food (151). In A. aegypti, NPF is also present in the brain and midgut of females, with titers being highest before and $24 \mathrm{~h}$ after a blood meal (125). A direct correlation between NPF injection and increased food uptake and weight gain is also seen in S. gregaria, where NPF knockdown results in weight loss (132).

Allatostatins (AST) and allatotropin (AT), two neuropeptide families initially discovered in cockroaches for their role in regulating juvenile hormone $(\mathrm{JH})$ release from the corpora allata, are also involved in feeding behavior. Insects can have one type of allatotropin and three types of allatostatins (type A, B and C). Injections of allatotropin suppresses feeding in the fall armyworm Spodoptera frugiperda, increases mortality in larvae and reduces lifespan in adults. Combined injections of AT and C-type AST have similar effects (103). Curiously, in a different moth Lacanobia oleracea, AT has no discernable effect on feeding or growth, while AST injections result in reduced feeding, decreased growth and increased mortality (7), an effect also seen in the tomato aphid (90), underscoring that neuropeptides 
can acquire distinct functions in separate species. In the silkworm, injection of AT or an AT-like peptide promotes latency to feed (99). Allatostatins A from the cockroach Blattela germanica inhibit food consumption (2). In Drosophila, activation of the AST-A-expressing neurons inhibits feeding in starved adults without mimicking satiety, as the metabolic changes accompanying a state of satiety aren't promoted (52). Activation of NPF-expressing neurons suppresses this inhibitory effect on feeding, suggesting a link between NPF and AST-A. Unfortunately, it isn't clear which other neuropeptides are released from these neurons. In addition, RNAi of Drosophila AST-A or its receptor induces a strong reduction in larval foraging in the presence of food (138). These effects are possibly regulated through insulin-like peptides (DILP) and adipokinetic hormone (AKH). The Drosophila AST-A receptor (DAR2) is present on AKH- and DILP-expressing cells of the CC. Silencing DAR-2 results in phenotypes comparable with DILP and AKH disruption. Insulin has a well-established role in feeding and energy metabolism in insects and meddling with the insulin pathway invariably has an effect on feeding, growth and lifespan. For instance, pan-neuronal overexpression of dilp2 and 4 reduces hunger-driven foraging in larvae (151). Disrupting IIS in Kenyon cells (important neurons in the mushroom bodies (MBs)) also results in decreased food acquisition (163). Starvation in flies leads to higher preferences for caloric sugars. This can be mimicked by mutating dilp2 and 3 and blocking the insulin receptor (124). The NPF/IIS signaling cascade may mediate a survival strategy that enables starving larvae to adapt to unfavorable conditions. The receptor NPFR1 is required for engaging in risk-prone food acquisition in deleteriously cold temperatures, while decreased expression of $\mathrm{InR}$ in the same cells was sufficient to induce high-risk feeding in fed larvae (85). This is consistent with the observation that down-regulating IIS in NPFR neurons induces feeding in fed larvae (151). In honey bees, downregulation of IIS also alters their behavior as it biases them towards protein-rich food (139).

One of the most potent inhibitors of food intake in B. germanica is myosuppressin (MS), which in high doses, is able to inhibit food uptake up to $75 \%$ (1). Also in $S$. littoralis, MS injection drastically inhibits feeding in larvae (135). In Bombyx, MS injection causes a prolonged latency period to the first bite. Contrarily, tachykinins 1 and 2 and sNPF1-3 reduce this period (100). Indeed, TKR RNAi leads to a decrease in body weight (51). Tachykinin is important in odor-based searching behavior of fruit flies. Several olfactory neurons contain high TK levels. RNAi of the peptide or receptor impairs odor preference towards indifference. In contrast, overexpression increases responsiveness to specific odorants $(56,148)$. Injection of tachykinins also results in diminished olfactory responses in electroantennograms (63). Leucokinins (LKs), neuropeptides with some resemblance to tachykinins are also important in regulating feeding. Mutations in leucokinin and its receptor in fruit flies results in an increase of meal size, but, due to a decrease in meal frequency, don't affect body weight (3). Blockade of LK release diminishes the preference for sweetness and increases responsiveness to aversive bitter tastes (88).

The insect hugin gene is homologous to vertebrate neuromedin $U$ and encodes neuropeptides designated as pyrokinins. Hugin-expressing neurons, which reside in the SOG, make contact with gustatory receptor cells suggesting they relay taste information. When flies are transferred to a new food source, they tend to wait for a certain period prior to feeding. This initiation depends on the quality of the previous food source and hunger state of the flies. Blocking transmission of hugin neurons causes adult flies to have completely filled crops after only 5 minutes, while control flies need 180 minutes to fill their crop (92). The authors concluded that hugin neurons regulate feeding initiation. Two other neuropeptides directly involved in feeding behavior are hypertrehalosemic hormone (HrTH) and CCHamide. HrTH belongs to the AKH-family and primarily evokes higher carbohydrate concentrations in the hemolymph. Additionally, in the blowfly Phormia regina, HrTH inhibits the crop lobe muscles (pump 5) and at the same time stimulates pump 4, which is involved in pushing fluids out of the crop. This shows that HrTH 
is likely involved in pumping carbohydrates from crop to midgut (126). The recently discovered CCHamide-2 augments feeding in blowflies (55). This is consistent with the reduced nutrient uptake and impaired locomotive activity caused by disruption of this gene in Drosophila (109). CCHamide-2 activates IPCs and disrupting its expression or that of its receptor $\mathrm{CCHa} 2 \mathrm{R}$ reduces expression levels of dilp2 and 5 (112). Silencing CCHa1R in Or59b-expressing olfactory neurons results in an abolished starvation effect (43). Other neuropeptides including proctolin, FMRFamides, capa, ion transport peptide (ITP), CCAP, diuretic hormones (DHs), antidiuretic peptides (ADPs), orcokinin, NPLP1, NVPlike, ITG, GPA2/GPB5, corazonin and AKH have been shown to either have an effect on the salivary glands, gut, digestion, diuresis or energy metabolism (8), but no direct link to feeding behavior has been observed.

It is obvious from these examples that manipulations of a single neuropeptide can cause similar effects for different peptides. Moreover, since many neuropeptides are co-released, it is very likely the entire cocktail of neuropeptides modulates or regulates the final sum of behavioral actions. Data have to be interpreted with care, because elimination or high concentrations of a particular peptide can provoke drastic phenotypes.

\section{Neuropeptides in reproductive behavior}

Courtship in fruit flies comprises of a series of well-defined steps such as chasing, avoiding, dancing, rejection and copulation, all of which involve intense locomotive activity. When virgin fruit fly females are confronted with a courting male, they usually readily mate. However, after mating their behavior drastically changes. They are no longer receptive, fend off approaching males and start to lay up to 80 eggs per day (77). This switch in behavior is primarily regulated by a single peptide present in male sperm, called sex peptide (SP) (87). Females mated with SP-deficient males show higher fitness and higher lifetime reproductive success, suggesting that SP comes at a high cost for females (146). The SP, also designated as the MIP-receptor is widely expressed in the CNS, but expression in doublesexneurons is (necessary and) sufficient for mediating postmating behavior (157). Injection of Drosophila SP into Helicoverpa armigera moths has a similar effect, inhibiting pheromone biosynthesis, suppressing calling behavior and Hea-MIP receptor expression (50). A well-known neuropeptide important in mating behavior in moths is PBAN (pheromone biosynthesis-activating neuropeptide). Knockdown in females results in decreased male attractiveness (79) as PBAN stimulates production of pheromones needed to attract mates. Repellent gustatory pheromones on the other hand function as potent suppressors of male courtship behavior. When a male fruit fly mates with a female, he leaves behind an anti-aphrodiasic pheromone, which deters the next male from mating with the female. A cluster of 8-10 neurons in the SOG mediates this decision through release of tachykinins (118).

Other neuropeptides involved in mating behavior include natalisin (59) and NPF. NPF is upregulated by mating and decreases upon sexual deprivation in male flies. Peculiarly, rejected flies have a higher preference for alcohol. Downregulation of NPF has a similar effect in mated flies, while activation of NPF neurons decreases alcohol preference in virgin males, mimicking a mated state (120). Ablation of male specific NPF neurons or NPF knockdown results in reduced male courtship behavior (80).

Males usually prolong their mating duration in the presence of competitors to increase the chance of successful gene transfer. In Drosophila, this effect requires the presence of both the NPFR1 receptor and pigment dispersing factor (PDF) in four s-LNv neurons as well as the PDF receptor and NPF in two LNd neurons (70). NPF neurons are also necessary for the detection of female sex pheromone (47), the production of which is under influence of IIS. Females with increased insulin production are more 
attractive to males, while reduced IIS has the opposite effect (78). In S. gregaria NPF injections promote copulation behavior and fertility in male locusts, besides stimulating vitellogenesis, oocyte growth and ecdysteriogenesis $(114,132)$. In flies, PDF mutants show an increased frequency of remating compared to wild-type flies (76). In addition, PDF-expressing vLNs contribute to male sex drive rhythm, which is disrupted when PDF isn't present (46). A remarkable change in phenotype is seen with reduction or absence of SIFamide in fruit flies. Males start vigorously courting both males and females, while females are extremely receptive (129). A similar effect is seen when the copper transporter ATP7 is knocked down in SIFamide-expressing neurons. This causes a decrease in mature amidated neuropeptides, probably due to a lack of functional PHM convertase, which contains copper. Flies affected in this manner display male-male courtship behavior (115).

Drosophila females also exhibit a characteristic sequence of behaviors when they lay their eggs. They prefer to lay them in medium that doesn't contain high sucrose levels. The few dilp 7 neurons in the CNS send projections to the SOG and female reproductive tract. Interestingly, females with hyperactivated dilp 7 neurons show no ovipositor motor programs. Elevation of just dilp 7 on the other hand causes flies to lay more eggs on the undesirable sucrose medium (156). The egg-laying decision is also influenced by the neuropeptide amnesiac (AMN). Flies lacking AMN display impaired decision-making behavior and don't distinguish between the unfavorable sucrose medium and the much preferred caffeine medium for laying their eggs. Expression of amn in two dorsal pair median neurons completely rescues this effect (149). During copulation, males coordinate mating length with the transfer of sperm and seminal fluid (SSFT). Silencing four abdominal ganglion interneurons containing corazonin (CRZ) blocked SSFT and lengthened copulation (128).

One typical set of behavior that is both involved in feeding behavior and reproduction is aggression. Aggression can ensure an individual has a better chance of survival if food is sparse or when multiple males wish to mate with the same female. Activation of the tachykinin gene in fruit flies resulted in higher intermale aggression. Surprisingly, the $T k^{+}$neurons were only present in males (6). A subset of these neurons also express $\mathrm{fru}^{+}$, a transcription factor important in courtship (153). Activation of the $\mathrm{Tk}^{+} / f r u^{+}$neurons also results in male to male aggression (154). In the presence of a female and absence of a male, activation of these neurons initiates courtship behavior, showing that courtship and intermale aggression are distinct circuits $(6,28)$. The convergence of aggression and sex within a common neuropeptidergic pathway suggests that the choice to fight or court is modulated by tachykinin release, which in part is triggered by external stimuli such as pheromones. Aggression (and mating behavior) are also influenced by the biogenic amine octopamine. Octopamine-regulated aggression in flies is modulated through drosulfakinin (DSK). In addition, DSK overexpression also induces hyperactivity (147). Interestingly, in mice CCK, the vertebrate homolog of DSK also regulates aggression (165). Genetic silencing of NPF also increases fly aggression (35). This is peculiar as RNAi of NPF inhibits courtship behavior (see earlier), which we intuitively relate to aggression.

\section{Neuropeptides in learning and memory}

Like other animals, insects can learn by training and can store information that might help them in future situations. One of the most studied neuropeptide genes involved in learning and memory is amnesiac. This neuropeptide was never biochemically isolated and seems to be dipteran-specific. Amn mutants show aberrant behavior in memory assays such as olfactory conditioning and shock reactivity $(44,108)$. Expression of amn in two dorsal paired medial neurons is sufficient for rescuing amn mutants $(34,137)$. Wild-type flies that learn to avoid dangerous odors will at a later time take into account both the temporal 
factor as the level of disadvantage. Amnesiac mutants make choices only according to the temporal factor, completely ignoring any danger (158). Amnesiac also affects taste discrimination between two different concentrations of sucrose (98). Long-term memory in odor-avoidance behavior is also affected in amn mutant larvae, in which memory length is reduced by half (69). Interestingly, aversive and appetitive memory differ in their retention time, with aversive conditioning forming short-time memories and appetitive conditioning forming stable memories. Both require an intact amn gene (27, 159). Amnesiac is also necessary for formation of cold-induced anesthesia-sensitive memory (ASM) as shown by using Pavlovian associative memory tests (82). The amn gene is also involved in nonassociative learning. Female flies usually avoid laying their eggs in alcohol-rich medium. In the presence of endoparasitoid wasps, female flies will suppress their oviposition rate to protect their offspring. But when ethanol-rich medium is in close proximity, female flies will actively lay eggs in this medium (fruit fly larvae are quite resistant to concentrations of up to $10 \%$ ethanol) and this preference is maintained for days after the wasps are removed. Flies lacking amn do not remember the wasp exposure and don't maintain their altered oviposition behavior after removal of the wasps (64).

Interestingly, also RNAi of NPF or NPFR1 increases the oviposition preference for ethanol, regardless of the presence of wasps, while overexpression has the opposite effect. Thus, visual perception of wasps may cause a decrease in NPF signaling (65). As mentioned earlier, stimulation of NPF neurons also promotes memory performance in satiated flies (74). This is remarkable as robust appetitive memory formation usually requires flies to be hungry (75). Drosophila larvae are able to associate odors with a fructose reward, which means they can be trained to choose between odors after conditioning. This appetitive memory formation is strongly impaired when NPF-expressing neurons are artificially activated. Moreover, activation of a single of the six NPF-expressing neurons in the larval brain is sufficient to interfere with appetitive memory. Aversive memory formation isn't affected (110). Olfactory memory also requires the snpf gene to be active in the Kenyon cells of the mushroom bodies. Snpf knockdown in Kenyon cells or of snpfr outside the MBs results in decreased sugar-rewarded olfactory memory (72). In honey bees, injection of allatostatins decreases appetitive olfactory learning (131).

\section{Neuropeptides involved in stress and addiction}

NPF, involved in all behaviors discussed so far, also plays a role in stress and addiction. Food-deprived insects may be forced to forage in dangerous conditions in order to ensure survival. Flies that are hungry will search for food in hostile cold temperatures. Yet lowering NPF in hungry larvae will cause them not to feed in cold environments. NPF overexpression causes even fed larvae to feed on the deleterious nutrients (85). Npfrl is expressed in a subset of painless neurons. Painless (pain) codes for a transient receptor potential channel that is involved in aversive responses to thermal, chemical and mechanical stressors. Npfr 1 knockdown in pain neurons abolishes larval aversion to sugar. On the other hand, $n p f r 1$ overexpression in these neurons blocks sugar-stimulated channel activity. Therefore, the NPF signaling pathway may have anti-nociceptive functions (152). Disrupting NPF/NPFR1 neurons in adults also confers resistance to ethanol sedation (143). Amn mutants show increased initial sensitivity to ethanol (17) and are less responsive to noxious heat stimulation. This shows that AMN is critical for thermal nociception (4). Similar to NPF, reducing corazonin in $c r z$-expressing neurons lowers ethanol sedation sensitivity (91). This is possibly regulated through alcohol dehydrogenase (ADH) as crz mutants have lower ADH levels (116). CRZ is thought to be the ortholog of vertebrate GnRH, which is directly regulated by stress hormones (26). Similarly, most $c r z$ neurons have receptors for DH31 and DH44, two diuretic neuropeptides that are orthologous to the mammalian stress hormones, calcitonin and CRF (61). 
Ablation of $c r z$-expressing neurons confers resistance to various stressors such as starvation, high salt concentration, and paraquat containing food to induce oxidative stress as measured by survival (164). Knocking down DH44 or its receptor increases desiccation tolerance, while LKR knockdown augmented resistance to starvation (22). A set of dorsal lateral peptidergic neurons (DLPs) communicating with IPCs is involved in stress responses as well. These cells express sNPF and CRZ and knockdown of either increases resistance to starvation (68). Three neuropeptides, ion transport peptide (ITP), sNPF and DTK, are co-expressed in five pairs of large protocerebral neurosecretory cells. Flies with reduced levels of DTK or SNPF, but not ITP, in these cells have difficulties to survive in dry and foodless environments (66). Targeted knockdown of DTKR, dilp5 or dInR in the principal cells of the Malphigian tubules also confers resistance to desiccative, oxidative and nutritional stress (122). Recently, Terhzaz and colleagues showed that yet another neuropeptide, capa, also renders fruit flies more resistant to desiccation when knocked down and, additionally, lengthens recovery time after coldstress (130). Many organisms experience augmented sleep after stressful events such as infection or heat shock. In Drosophila this stress-induced sleep is modulated by FMRFamide. Knockdown of this neuropeptide or its receptor causes reduced sleep after infection or heat-stress (83). A particular FMRFamide (DPKQDFMRFamide) also enhances the escape response from intense light exposure. Both FMRFamide and dromyosuppressin receptors are required for this behavior (71).

\section{Circadian rhythms, sleep and wakefulness}

Sleep is an essential behavior, conserved widely across animals. Sleep loss is detrimental to memory and learning performances as well as to health in general. Support for the hypothesis that the basic molecular mechanisms of sleep have been evolutionarily conserved across animal species is compelling. One of the most well-conserved pathways for sleep regulation is the circadian clock, composed of transcriptional feedback loops that were discovered in D. melanogaster (see $(14,39)$ ). Intrinsic rhythms in clock pacemaker neurons are coordinated by PDF and propagate to multiple downstream circuits to orchestrate behavioral rhythms. For instance, the leucokinin circuit connects these neurons to brain areas that regulate locomotive activity and sleep (25). Other neuropeptides involved in sleep and wakefulness regulation include ITP, SNPF, calcitonin-gene related peptide, amnesiac and SIFamide, which all have sleep-promoting functions $(39,53,117)$. PDF promotes arousal in Drosophila. Information on neuropeptidergic modulation of sleep in other insects is scarce. In Tribolium RNAi of orcokinin-A and -B resulted in longer death feigning (thanatosis) (58), a behavioral defense mechanism that helps to avoid attacks by jumper spiders (96). Orcokinin might thus be involved in inducing the "awakened" state of the beetles.

\section{Social behavior}

The social structure of honey bees is an ideal model for understanding how neuropeptides regulate social behavior. Although several peptidomics studies have revealed neuropeptide signatures associated with particular behaviors $(19,49)$, including labor division, causal evidence is scarce. Changes in IIS are associated with social behavior (5). In locusts, high levels of pyrokinin peptides are correlated with solitary behavior, whereas ITP is possibly associated with gregarious behavior (133). Removal of dead 
nest mates or necrophoretic behavior is thought to limit potential spread of pathogens within a social insect colony and is a common behavior in many ant species. Application of pyrokinins enhances this behavior (42).

\section{$\underline{\text { Conclusions and future perspectives }}$}

Synchronous light signaling of thousands of fireflies, procession marches of caterpillars, trap building or maintenance of mushroom farms by ant species, electric navigation in bumblebees, and swarm formation in locusts are examples of extraordinary and complex behaviors in insects. What is the molecular basis of such complex behaviors and how can variations in behaviors be explained from an evolutionary point of view? Driven by sensory information, neuropeptide signaling affects hardwired neuronal circuits. The neuropeptidergic state puts an extra layer on the regulation of behavioral output by modulating the functional output of neuronal circuits and shaping it over time by altering the circuit composition, its activity or dynamics.

It has been proposed that one route of behavioral evolution involves novel actions of conserved genes. For example, prothoracicotropic hormone (PTTH), a neuropeptide that controls the developmental transition from juvenile stage to sexual maturation, also modulates light avoidance behavior through its receptor Torso in Drosophila larvae (155). This photophobicity may ensure that wandering larvae maintain a preference for darkness, a condition that is required for successful pyrokinin-controlled pupariation (134). Another example concerns the role of vasopressin and oxytocin in social behavior, pair bonding, and parental care. It can be assumed that this role originated from their physiological functions. Reproduction would have been the driving force to use oxytocin for the regulation of parental care. Urine concentration under control of vasopressin would have been the antecedent of scent marking and territorial behavior in males. Recent studies contest this hypothesis and state that oxytocin's role in cognition does not derive from its physiological role, but is probably derived from its ancient function in associative learning (15), a function that more likely already originated when animals started to move to explore environments for food and for mates, behaviors that require decision-making and an experienced-based memory. It is clear that behavioral outputs evolved early in evolution.

In spite of the vast increase in insect neuropeptide research, only a small number of neuropeptides have so far been associated to behavioral outputs. The recent introduction of Crispr-Cas 9 technology in insect research is likely going to change this. Most of the studied insect neuropeptides are implicated in several distinct behaviors and thus able to integrate information from various cues to different behavioral outputs. Amnesiac and NPF for instance modulate feeding, reproductive, learning and stress behavior. Phenotypic diversity in behavioral output can be explained by species-specific sensory cues and variations in spatial and temporal expression of neuropeptides and their receptors. Also, most neuropeptidergic cells co-package neuropeptides into the same vesicles and thus release them simultaneously. Different neuronal cells can transcribe different subsets of neuropeptides. Additionally, neuropeptide transcripts can be differentially spliced and neuropeptides can be differentially sorted in the same cell. If you consider the sheer number of neuropeptides (most animals express over 100 neuropeptides) it is not difficult to picture the multiplicity of this network and the variation it can generate (18). This presents a huge problem when studying their function, which usually involves testing one or two neuropeptides at a time and observing the effects, while possibly dozens are set free simultaneously. The action of a single neuropeptide modulator is likely to be different from the action of the same modulator in the presence of another (18). This means that the standard paradigm in the best case, invariably leads to an oversimplification of the role of a particular neuropeptide. 
Some neuropeptides are able to activate two or more related receptors. The same receptor molecule may couple to different $\mathrm{G}$ proteins in different types of cells, leading to different outcomes. Ultimately this leads to an extremely large complexity in the neuropeptide network that is largely situated in interneurons, connecting sensory and motor neurons. It has already been shown that certain behaviors need a number of different neuropeptides to work in unison to bring the behavioral response to a successful conclusion. For instance, for ecdysis to work properly in Manduca sexta five neuropeptides are needed in sequential order (PETH, ETH, EH, CCAP, bursicon). In addition, other neuropeptides such as kinins, corazonin, MIPs, sNPF and FMRFamides, may play a role as well $(67,145)$. Park and co-workers showed that the Drosophila larval CNS harbors 24 different neuropeptides, each with a unique expression pattern, showing little overlap, with some cells expressing two to three different neuropeptides (105). This is in stark contrast to studies in the snail Lymnaea stagnalis where single cell mass spectrometry allowed detection of 17 distinct neuropeptides in one single neuron (60). In the near future this technique could potentially be used to target single neurons in the insect brain in order to provide us with a detailed map of neuropeptide contents of neurons to improve our understanding of neuronal networks.

Some neuropeptides and/or their receptors are absent in particular insect species. Other neuropeptides occur in multiple variants within a single species. Several studies indicate that neuropeptides and their receptors, if not hindered by structural constraints as with oxytocin, can rapidly co-evolve, resulting in the elimination of clear structural similarities among evolutionary related neuropeptides. The birth-anddeath evolution as well as co-evolution isn't uncommon for neuropeptide genes and their receptors and explains the enormous behavioral variation in various environmental contexts.

\section{Disclosure statement}

The authors are not aware of any affiliations, memberships, funding, or financial holdings that might be perceived as affecting the objectivity of this review.

\section{Acknowledgements}

We thank Dr. Kurt Boonen for the peptidome analysis of sponges and proofreading the manuscript. We apologize to those investigators whose work we could not refer to due to space limitations. The authors acknowledge the European Research Council (ERC-2013-ADG-340318) for financial support.

\section{Literature cited}

1. Aguilar R, Maestro JL, Vilaplana L, Chiva C, Andreu D, Belles X. 2004. Identification of leucomyosuppressin in the German cockroach, Blattella germanica, as an inhibitor of food intake. Regul Pept 119: 105-12

2. Aguilar R, Maestro JL, Vilaplana L, Pascual N, Piulachs MD, Belles X. 2003. Allatostatin gene expression in brain and midgut, and activity of synthetic allatostatins on feeding-related processes in the cockroach Blattella germanica. Regul Pept 115: 171-7

3. Al-Anzi B, Armand E, Nagamei P, Olszewski M, Sapin V, et al. 2010. The leucokinin pathway and its neurons regulate meal size in Drosophila. Curr Biol 20: 969-78

4. Aldrich BT, Kasuya J, Faron M, Ishimoto H, Kitamoto T. 2010. The amnesiac gene is involved in the regulation of thermal nociception in Drosophila melanogaster. J Neurogenet 24: $33-41$

5. Ament SA, Corona M, Pollock HS, Robinson GE. 2008. Insulin signaling is involved in the regulation of worker division of labor in honey bee colonies. Proc Natl Acad Sci U S A 105: 4226-31

6. Asahina K, Watanabe K, Duistermars BJ, Hoopfer E, Gonzalez CR, et al. 2014. Tachykininexpressing neurons control male-specific aggressive arousal in Drosophila. Cell 156: 221-35 
7. Audsley N, Duve H, Thorpe A, Weaver RJ. 2000. Morphological and physiological comparisons of two types of allatostatin in the brain and retrocerebral complex of the tomato moth, Lacanobia oleracea (Lepidoptera: Noctuidae). Journal of Comparative Neurology 424: $37-46$

8. Audsley N, Weaver RJ. 2009. Neuropeptides associated with the regulation of feeding in insects. Gen Comp Endocrinol 162: 93-104

9. Avargues-Weber A, Dyer AG, Ferrah N, Giurfa M. 2015. The forest or the trees: preference for global over local image processing is reversed by prior experience in honeybees. Proc Biol Sci 282: 20142384

10. Bandeira de Melo EB, Araujo AF. 2011. Modelling foraging ants in a dynamic and confined environment. Biosystems 104: 23-31

11. Bargmann CI. 2012. Beyond the connectome: how neuromodulators shape neural circuits. Bioessays 34: 458-65

12. Bateson M, Desire S, Gartside SE, Wright GA. 2011. Agitated honeybees exhibit pessimistic cognitive biases. Curr Biol 21: 1070-3

13. Bausenwein B, Muller NR, Heisenberg M. 1994. Behavior-dependent activity labeling in the central complex of Drosophila during controlled visual stimulation. Journal of Comparative Neurology 340: 255-68

14. Beckwith EJ, Ceriani MF. 2015. Communication between circadian clusters: The key to a plastic network. FEBS Lett 589: 3336-42

15. Beets I, Janssen T, Meelkop E, Temmerman L, Suetens N, et al. 2012. Vasopressin/oxytocinrelated signaling regulates gustatory associative learning in C. elegans. Science 338: 543-5

16. Beshel J, Zhong Y. 2013. Graded encoding of food odor value in the Drosophila brain. Journal of Neuroscience 33: 15693-704

17. Bhandari P, Kendler KS, Bettinger JC, Davies AG, Grotewiel M. 2009. An assay for evoked locomotor behavior in Drosophila reveals a role for integrins in ethanol sensitivity and rapid ethanol tolerance. Alcohol Clin Exp Res 33: 1794-805

18. Brezina V. 2010. Beyond the wiring diagram: signalling through complex neuromodulator networks. Philos Trans R Soc Lond B Biol Sci 365: 2363-74

19. Brockmann A, Annangudi SP, Richmond TA, Ament SA, Xie F, et al. 2009. Quantitative peptidomics reveal brain peptide signatures of behavior. Proc Natl Acad Sci U S A 106: 23838

20. Brown MR, Crim JW, Arata RC, Cai HN, Chun C, Shen P. 1999. Identification of a Drosophila brain-gut peptide related to the neuropeptide Y family. Peptides 20: 1035-42

21. Caers J, Boonen K, Van Den Abbeele J, Van Rompay L, Schoofs L, Van Hiel MB. 2015. Peptidomics of neuropeptidergic tissues of the tsetse fly Glossina morsitans morsitans. $\mathrm{J} \mathrm{Am}$ Soc Mass Spectrom 26: 2024-38

22. Cannell E, Dornan AJ, Halberg KA, Terhzaz S, Dow JA, Davies SA. 2016. The corticotropinreleasing factor-like diuretic hormone $44(\mathrm{DH})$ and kinin neuropeptides modulate desiccation and starvation tolerance in Drosophila melanogaster. Peptides

23. Carazo P, Font E, Forteza-Behrendt E, Desfilis E. 2009. Quantity discrimination in Tenebrio molitor: evidence of numerosity discrimination in an invertebrate? Anim Cogn 12: 463-70

24. Carlsson MA, Enell LE, Nassel DR. 2013. Distribution of short neuropeptide F and its receptor in neuronal circuits related to feeding in larval Drosophila. Cell and Tissue Research 353: 511-23

25. Cavey M, Collins B, Bertet C, Blau J. 2016. Circadian rhythms in neuronal activity propagate through output circuits. Nat Neurosci [Epub ahead of print]

26. Cazzamali G, Saxild N, Grimmelikhuijzen C. 2002. Molecular cloning and functional expression of a Drosophila corazonin receptor. Biochem Biophys Res Commun 298: 31-6

27. Cervantes-Sandoval I, Davis RL. 2012. Distinct traces for appetitive versus aversive olfactory memories in DPM neurons of Drosophila. Curr Biol 22: 1247-52

28. Chan YB, Kravitz EA. 2007. Specific subgroups of FruM neurons control sexually dimorphic patterns of aggression in Drosophila melanogaster. Proc Natl Acad Sci U S A 104: 19577-82

29. Changizi MA. 2003. Relationship between number of muscles, behavioral repertoire size, and encephalization in mammals. Journal of Theoretical Biology 220: 157-68 
30. Chen ME, Pietrantonio PV. 2006. The short neuropeptide F-like receptor from the red imported fire ant, Solenopsis invicta Buren (Hymenoptera: Formicidae). Arch Insect Biochem Physiol 61: 195-208

31. Chittka L, Niven J. 2009. Are Bigger Brains Better? Current Biology 19: R995-R1008

32. Chronwall BM, Zukowska Z. 2004. Neuropeptide Y, ubiquitous and elusive. Peptides 25: 359-63

33. Dacke M, Srinivasan MV. 2008. Evidence for counting in insects. Anim Cogn 11: 683-9

34. DeZazzo J, Xia S, Christensen J, Velinzon K, Tully T. 1999. Developmental expression of an $\mathrm{amn}(+)$ transgene rescues the mutant memory defect of amnesiac adults. Journal of Neuroscience 19: 8740-6

35. Dierick HA, Greenspan RJ. 2007. Serotonin and neuropeptide F have opposite modulatory effects on fly aggression. Nature Genetics 39: 678-82

36. Dillen S, Verdonck R, Zels S, Van Wielendaele P, Vanden Broeck J. 2014. Identification of the short neuropeptide F precursor in the desert locust: evidence for an inhibitory role of sNPF in the control of feeding. Peptides 53: 134-9

37. Dillen S, Zels S, Verlinden H, Spit J, Van Wielendaele P, Vanden Broeck J. 2013. Functional characterization of the short neuropeptide F receptor in the desert locust, Schistocerca gregaria. PLoS One 8: e53604

38. Dreier S, van Zweden JS, D'Ettorre P. 2007. Long-term memory of individual identity in ant queens. Biol Lett 3: 459-62

39. Dubowy CM, Cavanaugh DJ. 2014. Sleep: a neuropeptidergic wake-up call for flies. Curr Biol 24: R1092-4

40. Dussutour A, Deneubourg JL, Beshers S, Fourcassie V. 2009. Individual and collective problem-solving in a foraging context in the leaf-cutting ant Atta colombica. Anim Cogn 12: 21-30

41. Fairclough SR, Chen Z, Kramer E, Zeng Q, Young S, et al. 2013. Premetazoan genome evolution and the regulation of cell differentiation in the choanoflagellate Salpingoeca rosetta. Genome Biol 14: R15

42. Fan Y, Pereira RM, Kilic E, Casella G, Keyhani NO. 2012. Pyrokinin beta-neuropeptide affects necrophoretic behavior in fire ants (S. invicta), and expression of beta-NP in a mycoinsecticide increases its virulence. PLoS One 7: e26924

43. Farhan A, Gulati J, Grobetae-Wilde E, Vogel H, Hansson BS, Knaden M. 2013. The CCHamide 1 receptor modulates sensory perception and olfactory behavior in starved Drosophila. Sci Rep 3: 2765

44. Feany MB, Quinn WG. 1995. A neuropeptide gene defined by the Drosophila memory mutant amnesiac. Science 268: 869-73

45. Fricker LD. 2005. Neuropeptide-processing enzymes: applications for drug discovery. AAPS J 7: E449-55

46. Fujii S, Amrein H. 2010. Ventral lateral and DN1 clock neurons mediate distinct properties of male sex drive rhythm in Drosophila. Proc Natl Acad Sci U S A 107: 10590-5

47. Gendron CM, Kuo TH, Harvanek ZM, Chung BY, Yew JY, et al. 2014. Drosophila life span and physiology are modulated by sexual perception and reward. Science 343: 544-8

48. Giurfa M, Zhang S, Jenett A, Menzel R, Srinivasan MV. 2001. The concepts of 'sameness' and 'difference' in an insect. Nature 410: 930-3

49. Han B, Fang Y, Feng M, Hu H, Qi Y, et al. 2015. Quantitative neuropeptidome analysis reveals neuropeptides are correlated with social behavior regulation of the honeybee workers. Journal of Proteome Research 14: 4382-93

50. Hanin O, Azrielli A, Applebaum SW, Rafaeli A. 2012. Functional impact of silencing the Helicoverpa armigera sex-peptide receptor on female reproductive behaviour. Insect Molecular Biology 21: 161-7

51. He X, Zang J, Li X, Shao J, Yang H, et al. 2014. Activation of BNGR-A24 by direct interaction with tachykinin-related peptides from the silkworm Bombyx mori leads to the Gqand Gs-coupled signaling cascades. Biochemistry 53: 6667-78

52. Hergarden AC, Tayler TD, Anderson DJ. 2012. Allatostatin-A neurons inhibit feeding behavior in adult Drosophila. Proc Natl Acad Sci U S A 109: 3967-72 
53. Hermann-Luibl C, Yoshii T, Senthilan PR, Dircksen H, Helfrich-Forster C. 2014. The ion transport peptide is a new functional clock neuropeptide in the fruit fly Drosophila melanogaster. Journal of Neuroscience 34: 9522-36

54. Hong SH, Lee KS, Kwak SJ, Kim AK, Bai H, et al. 2012. Minibrain/Dyrk1a regulates food intake through the Sir2-FOXO-sNPF/NPY pathway in Drosophila and mammals. PLoS Genet 8: e1002857

55. Ida T, Takahashi T, Tominaga H, Sato T, Sano H, et al. 2012. Isolation of the bioactive peptides CCHamide-1 and CCHamide-2 from Drosophila and their putative role in appetite regulation as ligands for G protein-coupled receptors. Front Endocrinol (Lausanne) 3: 177

56. Ignell R, Root CM, Birse RT, Wang JW, Nassel DR, Winther AM. 2009. Presynaptic peptidergic modulation of olfactory receptor neurons in Drosophila. Proc Natl Acad Sci U S A 106: $13070-5$

57. Jekely G, Paps J, Nielsen C. 2015. The phylogenetic position of ctenophores and the origin(s) of nervous systems. Evodevo 6: 1

58. Jiang H, Kim HG, Park Y. 2015. Alternatively spliced orcokinin isoforms and their functions in Tribolium castaneum. Insect Biochem Mol Biol 65: 1-9

59. Jiang H, Lkhagva A, Daubnerova I, Chae HS, Simo L, et al. 2013. Natalisin, a tachykinin-like signaling system, regulates sexual activity and fecundity in insects. Proc Natl Acad Sci U S A 110: E3526-34

60. Jimenez CR, Spijker S, de Schipper S, Lodder JC, Janse CK, et al. 2006. Peptidomics of a single identified neuron reveals diversity of multiple neuropeptides with convergent actions on cellular excitability. Journal of Neuroscience 26: 518-29

61. Johnson EC, Shafer OT, Trigg JS, Park J, Schooley DA, et al. 2005. A novel diuretic hormone receptor in Drosophila: evidence for conservation of CGRP signaling. Journal of

Experimental Biology 208: 1239-46

62. Jorgensen EM. 2014. Animal evolution: looking for the first nervous system. Curr Biol 24: R655-8

63. Jung JW, Kim JH, Pfeiffer R, Ahn YJ, Page TL, Kwon HW. 2013. Neuromodulation of olfactory sensitivity in the peripheral olfactory organs of the American cockroach, Periplaneta americana. PLoS One 8: e81361

64. Kacsoh BZ, Bozler J, Hodge S, Ramaswami M, Bosco G. 2015. A novel paradigm for nonassociative long-term memory in Drosophila: predator-induced changes in oviposition behavior. Genetics 199: 1143-57

65. Kacsoh BZ, Lynch ZR, Mortimer NT, Schlenke TA. 2013. Fruit flies medicate offspring after seeing parasites. Science 339: 947-50

66. Kahsai L, Kapan N, Dircksen H, Winther AM, Nassel DR. 2010. Metabolic stress responses in Drosophila are modulated by brain neurosecretory cells that produce multiple neuropeptides. PLoS One 5: e11480

67. Kaneko Y, Hiruma K. 2014. Short neuropeptide F (sNPF) is a stage-specific suppressor for juvenile hormone biosynthesis by corpora allata, and a critical factor for the initiation of insect metamorphosis. Developmental Biology 393: 312-9

68. Kapan N, Lushchak OV, Luo J, Nassel DR. 2012. Identified peptidergic neurons in the Drosophila brain regulate insulin-producing cells, stress responses and metabolism by coexpressed short neuropeptide F and corazonin. Cell Mol Life Sci 69: 4051-66

69. Khurana S, Abu Baker MB, Siddiqi O. 2009. Odour avoidance learning in the larva of Drosophila melanogaster. J Biosci 34: 621-31

70. Kim WJ, Jan LY, Jan YN. 2013. A PDF/NPF neuropeptide signaling circuitry of male Drosophila melanogaster controls rival-induced prolonged mating. Neuron 80: 1190-205

71. Klose MK, Dason JS, Atwood HL, Boulianne GL, Mercier AJ. 2010. Peptide-induced modulation of synaptic transmission and escape response in Drosophila requires two Gprotein-coupled receptors. Journal of Neuroscience 30: 14724-34

72. Knapek S, Kahsai L, Winther AM, Tanimoto H, Nassel DR. 2013. Short neuropeptide F acts as a functional neuromodulator for olfactory memory in Kenyon cells of Drosophila mushroom bodies. Journal of Neuroscience 33: 5340-5 
73. Ko KI, Root CM, Lindsay SA, Zaninovich OA, Shepherd AK, et al. 2015. Starvation promotes concerted modulation of appetitive olfactory behavior via parallel neuromodulatory circuits. Elife 4

74. Krashes MJ, DasGupta S, Vreede A, White B, Armstrong JD, Waddell S. 2009. A neural circuit mechanism integrating motivational state with memory expression in Drosophila. Cell 139: 416-27

75. Krashes MJ, Waddell S. 2008. Rapid consolidation to a radish and protein synthesisdependent long-term memory after single-session appetitive olfactory conditioning in Drosophila. Journal of Neuroscience 28: 3103-13

76. Krupp JJ, Billeter JC, Wong A, Choi C, Nitabach MN, Levine JD. 2013. Pigment-dispersing factor modulates pheromone production in clock cells that influence mating in Drosophila. Neuron 79: 54-68

77. Kubli E, Bopp D. 2012. Sexual behavior: how Sex Peptide flips the postmating switch of female flies. Curr Biol 22: R520-2

78. Kuo TH, Fedina TY, Hansen I, Dreisewerd K, Dierick HA, et al. 2012. Insulin signaling mediates sexual attractiveness in Drosophila. PLoS Genet 8: e1002684

79. Lee DW, Shrestha S, Kim AY, Park SJ, Yang CY, et al. 2011. RNA interference of pheromone biosynthesis-activating neuropeptide receptor suppresses mating behavior by inhibiting sex pheromone production in Plutella xylostella (L.). Insect Biochem Mol Biol 41: 236-43

80. Lee G, Bahn JH, Park JH. 2006. Sex- and clock-controlled expression of the neuropeptide F gene in Drosophila. Proc Natl Acad Sci U S A 103: 12580-5

81. Lee KS, You KH, Choo JK, Han YM, Yu K. 2004. Drosophila short neuropeptide F regulates food intake and body size. J Biol Chem 279: 50781-9

82. Lee PT, Lin HW, Chang YH, Fu TF, Dubnau J, et al. 2011. Serotonin-mushroom body circuit modulating the formation of anesthesia-resistant memory in Drosophila. Proc Natl Acad Sci U $S$ A 108: 13794-9

83. Lenz O, Xiong J, Nelson MD, Raizen DM, Williams JA. 2015. FMRFamide signaling promotes stress-induced sleep in Drosophila. Brain Behav Immun 47: 141-8

84. Liesch J, Bellani LL, Vosshall LB. 2013. Functional and genetic characterization of neuropeptide Y-like receptors in Aedes aegypti. PLoS Negl Trop Dis 7: e2486

85. Lingo PR, Zhao Z, Shen P. 2007. Co-regulation of cold-resistant food acquisition by insulinand neuropeptide Y-like systems in Drosophila melanogaster. Neuroscience 148: 371-4

86. Linnaeus C. 1758. Systema naturae per regna tria naturae :secundum classes, ordines, genera, species, cum characteribus, differentiis, synonymis, locis: Stockholm: Laurentius Salvius.

87. Liu H, Kubli E. 2003. Sex-peptide is the molecular basis of the sperm effect in Drosophila melanogaster. Proc Natl Acad Sci U S A 100: 9929-33

88. Lopez-Arias B, Dorado B, Herrero P. 2011. Blockade of the release of the neuropeptide leucokinin to determine its possible functions in fly behavior: chemoreception assays.

Peptides 32: 545-52

89. Maestro JL, Aguilar R, Pascual N, Valero ML, Piulachs MD, et al. 2001. Screening of antifeedant activity in brain extracts led to the identification of sulfakinin as a satiety promoter in the German cockroach. Are arthropod sulfakinins homologous to vertebrate gastrinscholecystokinins? Eur J Biochem 268: 5824-30

90. Matthews HJ, Down RE, Audsley N. 2010. Effects of Manduca sexta allatostatin and an analogue on the peach-potato aphid Myzus persicae (hemiptera: aphididae) and degradation by enzymes in the aphid gut. Arch Insect Biochem Physiol 75: 139-57

91. McClure KD, Heberlein U. 2013. A small group of neurosecretory cells expressing the transcriptional regulator apontic and the neuropeptide corazonin mediate ethanol sedation in Drosophila. Journal of Neuroscience 33: 4044-54

92. Melcher C, Pankratz MJ. 2005. Candidate gustatory Interneurons modulating feeding behavior in the Drosophila brain. Plos Biology 3: 1618-29

93. Meyering-Vos M, Muller A. 2007. RNA interference suggests sulfakinins as satiety effectors in the cricket Gryllus bimaculatus. J Insect Physiol 53: 840-8 
94. Mikani A, Wang QS, Takeda M. 2012. Brain-midgut short neuropeptide F mechanism that inhibits digestive activity of the American cockroach, Periplaneta americana upon starvation. Peptides 34: 135-44

95. Mikani A, Watari Y, Takeda M. 2015. Brain-midgut cross-talk and autocrine metabolastat via the sNPF/CCAP negative feed-back loop in the American cockroach, Periplaneta americana. Cell and Tissue Research 362: 481-96

96. Miyatake T, Katayama K, Takeda Y, Nakashima A, Sugita A, Mizumoto M. 2004. Is deathfeigning adaptive? Heritable variation in fitness difference of death-feigning behaviour. Proc Biol Sci 271: 2293-6

97. Moroz LL, Kocot KM, Citarella MR, Dosung S, Norekian TP, et al. 2014. The ctenophore genome and the evolutionary origins of neural systems. Nature 510: 109-14

98. Motosaka K, Koganezawa M, Narikawa S, Furuyama A, Shinozaki K, et al. 2007. Cyclic AMP-dependent memory mutants are defective in the food choice behavior of Drosophila. $J$ Comp Physiol A Neuroethol Sens Neural Behav Physiol 193: 279-83

99. Nagata S, Matsumoto S, Nakane T, Ohara A, Morooka N, et al. 2012. Effects of starvation on brain short neuropeptide F-1, -2 , and -3 levels and short neuropeptide $\mathrm{F}$ receptor expression levels of the silkworm, Bombyx mori. Front Endocrinol (Lausanne) 3: 3

100. Nagata S, Morooka N, Matsumoto S, Kawai T, Nagasawa H. 2011. Effects of neuropeptides on feeding initiation in larvae of the silkworm, Bombyx mori. Gen Comp Endocrinol 172: 90-5

101. Nassel DR, Enell LE, Santos JG, Wegener C, Johard HA. 2008. A large population of diverse neurons in the Drosophila central nervous system expresses short neuropeptide F, suggesting multiple distributed peptide functions. BMC Neurosci 9: 90

102. Nassel DR, Winther AM. 2010. Drosophila neuropeptides in regulation of physiology and behavior. Progress in Neurobiology 92: 42-104

103. Oeh U, Lorenz MW, Dyker H, Losel P, Hoffmann KH. 2000. Interaction between Manduca sexta allatotropin and manduca sexta allatostatin in the fall armyworm Spodoptera frugiperda. Insect Biochem Mol Biol 30: 719-27

104. Pahl M, Si A, Zhang S. 2013. Numerical cognition in bees and other insects. Front Psychol 4: 162

105. Park D, Veenstra JA, Park JH, Taghert PH. 2008. Mapping peptidergic cells in Drosophila: where DIMM fits in. PLoS One 3: e1896

106. Peterson KJ, Butterfield NJ. 2005. Origin of the Eumetazoa: testing ecological predictions of molecular clocks against the Proterozoic fossil record. Proc Natl Acad Sci U S A 102: 9547-52

107. Predel R, Russell WK, Russell DH, Lopez J, Esquivel J, Nachman RJ. 2008. Comparative peptidomics of four related hemipteran species: pyrokinins, myosuppressin, corazonin, adipokinetic hormone, SNPF, and periviscerokinins. Peptides 29: 162-7

108. Quinn WG, Sziber PP, Booker R. 1979. The Drosophila memory mutant amnesiac. Nature 277: $212-4$

109. Ren GR, Hauser F, Rewitz KF, Kondo S, Engelbrecht AF, et al. 2015. CCHamide-2 Is an Orexigenic Brain-Gut Peptide in Drosophila. PLoS One 10: e0133017

110. Rohwedder A, Selcho M, Chassot B, Thum AS. 2015. Neuropeptide F neurons modulate sugar reward during associative olfactory learning of Drosophila larvae. Journal of Comparative Neurology 523: 2637-64

111. Root CM, Ko KI, Jafari A, Wang JW. 2011. Presynaptic facilitation by neuropeptide signaling mediates odor-driven food search. Cell 145: 133-44

112. Sano H, Nakamura A, Texada MJ, Truman JW, Ishimoto H, et al. 2015. The nutrientresponsive hormone CCHamide-2 controls growth by regulating insulin-like peptides in the brain of Drosophila melanogaster. PLoS Genet 11: e1005209

113. Sato C, Matsumoto Y, Sakura M, Mizunami M. 2006. Contextual olfactory learning in cockroaches. Neuroreport 17: 553-7

114. Schoofs L, Clynen E, Cerstiaens A, Baggerman G, Wei Z, et al. 2001. Newly discovered functions for some myotropic neuropeptides in locusts. Peptides 22: 219-27

115. Sellami A, Wegener C, Veenstra JA. 2012. Functional significance of the copper transporter ATP7 in peptidergic neurons and endocrine cells in Drosophila melanogaster. FEBS Lett 586: 3633-8 
116. Sha K, Choi SH, Im J, Lee GG, Loeffler F, Park JH. 2014. Regulation of ethanol-related behavior and ethanol metabolism by the Corazonin neurons and Corazonin receptor in Drosophila melanogaster. PLoS One 9: e87062

117. Shang Y, Donelson NC, Vecsey CG, Guo F, Rosbash M, Griffith LC. 2013. Short neuropeptide $\mathrm{F}$ is a sleep-promoting inhibitory modulator. Neuron 80: 171-83

118. Shankar S, Chua JY, Tan KJ, Calvert ME, Weng R, et al. 2015. The neuropeptide tachykinin is essential for pheromone detection in a gustatory neural circuit. Elife 4: e06914

119. Sheehan MJ, Tibbetts EA. 2011. Specialized face learning is associated with individual recognition in paper wasps. Science 334: 1272-5

120. Shohat-Ophir G, Kaun KR, Azanchi R, Mohammed H, Heberlein U. 2012. Sexual deprivation increases ethanol intake in Drosophila. Science 335: 1351-5

121. Smith CL, Varoqueaux F, Kittelmann M, Azzam RN, Cooper B, et al. 2014. Novel cell types, neurosecretory cells, and body plan of the early-diverging metazoan Trichoplax adhaerens.

Curr Biol 24: 1565-72

122. Soderberg JA, Birse RT, Nassel DR. 2011. Insulin production and signaling in renal tubules of Drosophila is under control of tachykinin-related peptide and regulates stress resistance. PLoS One 6: e19866

123. Soderberg JA, Carlsson MA, Nassel DR. 2012. Insulin-producing cells in the Drosophila brain also express satiety-inducing cholecystokinin-like peptide, Drosulfakinin. Front Endocrinol (Lausanne) 3: 109

124. Stafford JW, Lynd KM, Jung AY, Gordon MD. 2012. Integration of taste and calorie sensing in Drosophila. Journal of Neuroscience 32: 14767-74

125. Stanek DM, Pohl J, Crim JW, Brown MR. 2002. Neuropeptide F and its expression in the yellow fever mosquito, Aedes aegypti. Peptides 23: 1367-78

126. Stoffolano JG, Jr., Croke K, Chambers J, Gade G, Solari P, Liscia A. 2014. Role of PhoteHrTH (Phormia terraenovae hypertrehalosemic hormone) in modulating the supercontractile muscles of the crop of adult Phormia regina Meigen. J Insect Physiol 71: 147-55

127. Takahashi T, Takeda N. 2015. Insight into the molecular and functional diversity of cnidarian neuropeptides. Int J Mol Sci 16: 2610-25

128. Tayler TD, Pacheco DA, Hergarden AC, Murthy M, Anderson DJ. 2012. A neuropeptide circuit that coordinates sperm transfer and copulation duration in Drosophila. Proc Natl Acad Sci U S A 109: 20697-702

129. Terhzaz S, Rosay P, Goodwin SF, Veenstra JA. 2007. The neuropeptide SIFamide modulates sexual behavior in Drosophila. Biochemical and Biophysical Research Communications 352: 305-10

130. Terhzaz S, Teets NM, Cabrero P, Henderson L, Ritchie MG, et al. 2015. Insect capa neuropeptides impact desiccation and cold tolerance. Proc Natl Acad Sci U S A 112: 2882-7

131. Urlacher E, Soustelle L, Parmentier ML, Verlinden H, Gherardi MJ, et al. 2016. Honey bee allatostatins target galanin/somatostatin-like receptors and modulate learning: A conserved function? PLoS One 11: e0146248

132. Van Wielendaele P, Wynant N, Dillen S, Badisco L, Marchal E, Vanden Broeck J. 2013. In vivo effect of Neuropeptide $\mathrm{F}$ on ecdysteroidogenesis in adult female desert locusts (Schistocerca gregaria). J Insect Physiol 59: 624-30

133. Verdonck R, De Haes W, Cardoen D, Menschaert G, Huhn T, et al. 2016. Fast and reliable quantitative peptidomics with labelpepmatch. Journal of Proteome Research 15: 1080-9

134. Verleyen P, Clynen E, Huybrechts J, Van Lommel A, Vanden Bosch L, et al. 2004. Fraenkel's pupariation factor identified at last. Developmental Biology 273: 38-47

135. Vilaplana L, Pascual N, Perera N, Leira D, Belles X. 2008. Antifeeding properties of myosuppressin in a generalist phytophagous leafworm, Spodoptera littoralis (Boisduval). Regul Pept 148: 68-75

136. von Frisch K. 1965. Tanzsprache und Orientierung der Bienen Springer-Verlag Berlin/Heidelberg/New York

137. Waddell S, Armstrong JD, Kitamoto T, Kaiser K, Quinn WG. 2000. The amnesiac gene product is expressed in two neurons in the Drosophila brain that are critical for memory. Cell 103: $805-13$ 
138. Wang C, Chin-Sang I, Bendena WG. 2012. The FGLamide-allatostatins influence foraging behavior in Drosophila melanogaster. PLoS One 7: e36059

139. Wang Y, Mutti NS, Ihle KE, Siegel A, Dolezal AG, et al. 2010. Down-regulation of honey bee IRS gene biases behavior toward food rich in protein. PLoS Genet 6: e1000896

140. Wang Y, Pu Y, Shen P. 2013. Neuropeptide-gated perception of appetitive olfactory inputs in Drosophila larvae. Cell Rep 3: 820-30

141. Watanabe H, Mizunami M. 2007. Pavlov's cockroach: classical conditioning of salivation in an insect. PLoS One 2: e529

142. Wei Z, Baggerman G, R JN, Goldsworthy G, Verhaert P, et al. 2000. Sulfakinins reduce food intake in the desert locust, Schistocerca gregaria. J Insect Physiol 46: 1259-65

143. Wen TQ, Parrish CA, Xu D, Wu Q, Shen P. 2005. Drosophila neuropeptide F and its receptor, NPFR1, define a signaling pathway that acutely modulates alcohol sensitivity. Proceedings of the National Academy of Sciences of the United States of America 102: 2141-46

144. Whalan S, Webster NS. 2014. Sponge larval settlement cues: the role of microbial biofilms in a warming ocean. Sci Rep 4: 4072

145. White BH, Ewer J. 2014. Neural and hormonal control of postecdysial behaviors in insects. Annual Review of Entomology 59: 363-81

146. Wigby S, Chapman T. 2005. Sex peptide causes mating costs in female Drosophila melanogaster. Curr Biol 15: 316-21

147. Williams MJ, Goergen P, Rajendran J, Klockars A, Kasagiannis A, et al. 2014. Regulation of aggression by obesity-linked genes TfAP-2 and Twz through octopamine signaling in Drosophila. Genetics 196: 349-62

148. Winther AM, Acebes A, Ferrus A. 2006. Tachykinin-related peptides modulate odor perception and locomotor activity in Drosophila. Molecular and Cellular Neuroscience 31: 399-406

149. Wu CL, Fu TF, Chou YY, Yeh SR. 2015. A single pair of neurons modulates egg-laying decisions in Drosophila. PLoS One 10: e0121335

150. Wu Q, Wen T, Lee G, Park JH, Cai HN, Shen P. 2003. Developmental control of foraging and social behavior by the Drosophila neuropeptide Y-like system. Neuron 39: 147-61

151. Wu Q, Zhao Z, Shen P. 2005. Regulation of aversion to noxious food by Drosophila neuropeptide Y- and insulin-like systems. Nat Neurosci 8: 1350-5

152. Xu J, Li M, Shen P. 2010. A G-protein-coupled neuropeptide Y-like receptor suppresses behavioral and sensory response to multiple stressful stimuli in Drosophila. Journal of Neuroscience 30: 2504-12

153. Yamamoto D. 2008. Brain sex differences and function of the fruitless gene in Drosophila. $J$ Neurogenet 22: 309-32

154. Yamamoto D, Koganezawa M. 2013. Genes and circuits of courtship behaviour in Drosophila males. Nat Rev Neurosci 14: 681-92

155. Yamanaka N, Romero NM, Martin FA, Rewitz KF, Sun M, et al. 2013. Neuroendocrine control of Drosophila larval light preference. Science 341: 1113-6

156. Yang CH, Belawat P, Hafen E, Jan LY, Jan YN. 2008. Drosophila egg-laying site selection as a system to study simple decision-making processes. Science 319: 1679-83

157. Yapici N, Kim YJ, Ribeiro C, Dickson BJ. 2008. A receptor that mediates the post-mating switch in Drosophila reproductive behaviour. Nature 451: 33-7

158. Yin Y, Chen N, Zhang S, Guo A. 2009. Choice strategies in Drosophila are based on competition between olfactory memories. Eur J Neurosci 30: 279-88

159. Yu D, Keene AC, Srivatsan A, Waddell S, Davis RL. 2005. Drosophila DPM neurons form a delayed and branch-specific memory trace after olfactory classical conditioning. Cell 123: 945-57

160. Yu N, Nachman RJ, Smagghe G. 2013. Characterization of sulfakinin and sulfakinin receptor and their roles in food intake in the red flour beetle Tribolium castaneum. Gen Comp Endocrinol 188: 196-203

161. Zels S, Dillen S, Crabbe K, Spit J, Nachman RJ, Vanden Broeck J. 2015. Sulfakinin is an important regulator of digestive processes in the migratory locust, Locusta migratoria. Insect Biochem Mol Biol 61: 8-16 
162. Zhang S, Mizutani A, Srinivasan MV. 2000. Maze navigation by honeybees: learning path regularity. Learn Mem 7: 363-74

163. Zhao XL, Campos AR. 2012. Insulin signalling in mushroom body neurons regulates feeding behaviour in Drosophila larvae. Journal of Experimental Biology 215: 2696-702

164. Zhao Y, Bretz CA, Hawksworth SA, Hirsh J, Johnson EC. 2010. Corazonin neurons function in sexually dimorphic circuitry that shape behavioral responses to stress in Drosophila. PLoS One 5: e9141

165. Zwanzger P, Domschke K, Bradwejn J. 2012. Neuronal network of panic disorder: the role of the neuropeptide cholecystokinin. Depress Anxiety 29: 762-74 